\title{
Correction to: Respiratory tract infection-related healthcare utilisation in children with Down's syndrome
}

\author{
Logan Manikam ${ }^{1,2} \cdot$ Anne G. M. Schilder ${ }^{3,4} \cdot$ Monica Lakhanpaul $^{5,6} \cdot$ Peter Littlejohns $^{7} \cdot$ Emma C. Alexander $^{8}$. \\ Andrew Hayward ${ }^{1,2}$
}

Published online: 27 April 2020

(c) The Author(s) 2020

\section{Correction to: Infection https://doi.org/10.1007/s15010-020-01408-5}

The original version of this article unfortunately contained an omission.

The Acknowledgements section was missing. The Acknowledgements are now given below.

Acknowledgements The authors would like to thank Dr Stefano Cacciatore, Ms Meghan Cupp, Ms Natalie Fitzpatrick, Prof Spiros Denaxas, Dr Arturo Gonzalez-Izquierdo, Mr Kenan Direk, Dr Charlotte Warren-Gash, Mr Nishchay Mehta, Denise Beales, Giovanna Ceroni, Dr Jill Ellis, Dr Hannah Evans and Prof Rolf Groenwold for their advice and assistance provided in undertaking this study. The authors would additionally like to thank our patient and public involvement panel consisting of Donna Self and Lindsey Fairchild (parents of children with Down's Syndrome) and representatives from the Down's
Syndrome Association (Stuart Mills and Vanda Ridley) who assisted in research design, analyses, interpretation and dissemination throughout the study.

Open Access This article is licensed under a Creative Commons Attribution 4.0 International License, which permits use, sharing, adaptation, distribution and reproduction in any medium or format, as long as you give appropriate credit to the original author(s) and the source, provide a link to the Creative Commons licence, and indicate if changes were made. The images or other third party material in this article are included in the article's Creative Commons licence, unless indicated otherwise in a credit line to the material. If material is not included in the article's Creative Commons licence and your intended use is not permitted by statutory regulation or exceeds the permitted use, you will need to obtain permission directly from the copyright holder. To view a copy of this licence, visit http://creativecommons.org/licenses/by/4.0/.
The original article can be found online at https://doi.org/10.1007/ s15010-020-01408-5.

\section{Logan Manikam}

logan.manikam.10@alumni.ucl.ac.uk

1 UCL Institute of Epidemiology and Healthcare, University College London, 1-19 Torrington Place, London WC1E 6BT, UK

2 UCL Institute of Health Informatics Research, University College London, 222 Euston Road, London NW1 2DA, UK

3 National Institute of Health Research University College London Hospitals Biomedical Research Centre, 149 Tottenham Court Road, London W1T 7DN, UK

4 evidENT, UCL Ear Institute, University College London, 332 Grays Inn Road, London WC1X 8DA, UK
5 Population, Policy \& Practice, UCL Great Ormond Street Institute of Child Health, University College London, 30 Guilford Street, London WC1N 1EH, UK

6 Whittington Health NHS Trust, Magdala Avenue, London N19 5NF, UK

7 Centre for Implementation Science, Institute of Psychiatry, Psychology and Neurosciences, King's College London, 6 De Crespigny Park, Camberwell, London SE5 8AB, UK

8 Paediatric Liver, GI and Nutrition Centre and Mowatlabs, King's College Hospital, Denmark Hill, London SE5 9RS, UK 